\title{
EFISIENSI PEMASARAN KERIPIK KELAPA \\ (Studi Kasus pada PT. Dinaya Sambiana Loemintoe di Dusun Cikoranji Desa Cimindi Kecamatan Cigugur Kabupaten Pangandaran)
}

\author{
DEWI PERMATASARI ${ }^{*}$, BUDI SETIA ${ }^{1}$, SUDRAJAT $^{1}$ \\ ${ }^{1}$ Fakultas Pertanian Universitas Galuh \\ *E-mail: dp24091997@gmail.com
}

\begin{abstract}
ABSTRAK
Penelitian ini bertujuan untuk mengetahui 1) saluran pemasaran keripik kelapa pada PT. Dinaya Sambiana Loemintoe di Dusun Cikoranji Desa Cimindi Kecamatan Cigugur Kabupaten Pangandaran. 2) besarnya biaya di tiap saluran pemasaran yang dikeluarkan oleh lembaga pemasaran. 3) besarnya marjin dan keuntungan pemasaran di tiap saluran pemasaran yang dikeluarkan oleh lembaga pemasaran. 4) efisiensi saluran pemasaran keripik kelapa. Penelitian ini dilaksanakan dengan menggunakan metode studi kasus data yang dikumpulkan meliputi data primer dan data sekunder. Teknik pengambilan sampel untuk lokasi penelitian adalah purposive sampling, sedangkan lembaga pemasaran dengan cara snowball sampling. Hasil penelitian menunjukkan :1) Pemasaran keripik kelapa pada PT. Dinaya Sambiana Loemintoe yang berada di Dusun Cikoranji Desa Cimindi Kecamatan Cigugur Kabupaten Pangandaran memiliki dua jenis saluran pemasaran meliputi agen dan pedagang pengecer,. 2) Biaya Pemasaran di Tiap Saluran Pemasaran pada saluran I untuk agen meliputi biaya bongkar muat, transportasi dan retribusi yaitu $\mathrm{Rp} 2.250,00 / \mathrm{kg}$, sedangkan pada saluran II untuk agen yaitu $\mathrm{Rp} 550,75 / \mathrm{kg}$. sedangkan untuk pedagang pengecer meliputi biaya kemasan dan biaya angkut Rp 1.023,648/kg. 3) Marjin Pemasaran di Tiap Saluran Pemasaran pada saluran I untuk agen sebesar Rp 17.000,00/kg majin pemasaran pada saluran II untuk agen sebesar Rp 12.000,00/kg dan pedagang pengecer sebesar Rp 13.500,00/kg. Sedangkan keuntungan pemasaran di tiap saluran pemasaran pada saluran I untuk agen sebesar Rp 14.750,00/kg, keuntungan pada saluran II untuk agen sebesar Rp 11.449,25/kg dan pedagang pengecer sebesar 11.263,420/kg. 4) Secara menyeluruh dapat dikatakan bahwa pemasaran keripik kelapa pada PT. Dinaya Sambiana Loemintoe yang berada di Dusun Cikoranji Desa Cimindi Kecamatan Cigugur Kabupaten Pangandaran tergolong dalam kategori efisien.
\end{abstract}

Kata Kunci : Pemasaran Keripik Kelapa, Efisiensi Pemasaran, Saluran Pemasaran

\section{PENDAHULUAN}

Sektor Pertanian memegang

peranan yang sangat penting dalam

perekonomian di Indonesia, baik sebagai

sumber pertumbuhan, lapangan kerja,

pendapatan, maupun sumber devisa

Negara (Deliarnov, 2006). Pembangunan

Pertanian di Jawa Barat tetap merupakan

bagian terpenting dari pembangunan

ekonomi nasional, rata-rata penduduk di

Jawa Barat menggantungkan hidupnya

dari sektor pertanian baik secara langsung maupun tidak langsung. Sektor Pertanian dapat terus memberikan peranan penting pada perekonomian Indonesia. Diperlukan adanya suatu perencanaan pembangunan di sektor ini, salah satunya adalah bisnis dibidang pertanian (Sjamsir, 2007).

Menurut Faqih (2010) agribisnis adalah suatu sistem dimana keberhasilan agribisnis sangat dipengaruhi oleh keberadaan komponen-komponen yang ada dalam system agribisnis tersebut dan faktor-faktor lingkungan di sekitarnya. 
Sebagai subjek akademik, agribisnis mempelajari strategi memperoleh keuntungan dengan mengelola aspek budidaya, penyediaan bahan baku, pascapanen, proses pengolahan, hingga tahap pemasaran.

Salah satu komoditas pertanian yang memiliki potensi menjanjikan dalam meningkatkan perekonomian nasional adalah tanaman kelapa. Tanaman kelapa (Cocos nucifera L) merupakan salah satu tanaman industri yang memegang peranan penting dalam perekonomian di Indonesia. Hal ini berkaitan erat dengan usaha pemerintah setempat untuk meningkatkan pendapatan daerah dan kegiatan ekonomi masyarakat. Selain itu dapat dipastikan bahwa seluruh masyarakat Indonesia mengenal tanaman kelapa karena tanaman tersebut tersebar di seluruh wilayah Indonesia (Winarno, 2014). Umumnya masyarakat di Kabupaten Pangandaran mengolah daging buah kelapa hanya sebatas pengolahan kopra, minyak kelapa, dan santan sebagai kebutuhan industri maupun rumah tangga. Salah satu bentuk pengolahan daging buah kelapa yang masih asing terdengar dan kurang dikenal oleh masyarakat Pangandaran yakni keripik kelapa. Pabrik pengolahan keripik kelapa yang berada di Kecamatan Cigugur adalah satu-satunya perusahaan yang mengolah daging buah menjadi keripik kelapa di Kabupaten Pangandaran.

PT. Dinaya Sambiana Loemintoe yang berada di Dusun Cikoranji Desa Cimindi Kecamatan Cigugur Kabupaten Pangandaran merupakan perusahaan agroindustri yang memproduksi keripik kelapa dan letaknya sangat strategis, dimana perusahaan tersebut terletak tidak jauh dari pasar dan dari perkebunan kelapa sehingga mudah untuk mendapatkan supply bahan baku dari pengepul maupun petani kelapa yang ada di daerah tersebut.

$$
\text { Dalam menjalankan proses }
$$
produksi hingga sampai ke konsumen tentunya melalui beberapa saluran pemasaran. Peranan utama dari saluran pemasaran adalah untuk memastikan bahwa produk yang tepat, tersedia pada waktu yang tepat. Ini menunjukkan pentingnya pengelolaan saluran pemasaran mulai dari sumber pasokan awal hingga sampai ke konsumen (Suryanto, 2017).

Panjang pendeknya rantai pemasaran akan menentukan efisiensi pemasaran. Efisiensi pemasaran dapat diukur dengan membandingkan biaya pemasaran yang dikeluarkan terhadap nilai produk yang dipasarkan atau harga jual produk ditingkat eceran. Kemudian rasio ini dapat dikonversikan ke persen. Pemasaran yang efisien jika biaya 
pemasaran yang digunakan lebih rendah dari nilai produk yang dipasarkan (Abidin dkk, 2017)

Hal penting dalam pemasaran produk pertanian adalah konsistensi masing-masing pihak untuk menjalankan fungsinya dan pembagian imbalan secara adil, sehingga petani mendapatkan keuntungan yang layak dari pemasaran produk yang dihasilkannya. Berdasarkan uraian tersebut maka penulis tertarik untuk melakukan penelitian mengenai efisiensi pemasaran keripik kelapa pada PT. Dinaya Sambiana Loemintoe di Dusun Cikoranji Desa Cimindi Kecamatan Cigugur Kabupaten Pangandaran.

\section{METODE PENELITIAN}

\section{Jenis Penelitian}

Jenis penelitian yang digunakan dalam penelitian ini adalah studi kasus, dengan mengambil kasus pada PT. Dinaya Sambiana Loemintoe di Dusun Cikoranji Desa Cimindi Kecamatan Cigugur Kabupaten Pangandaran. Menurut Waluya (2004), studi kasus adalah suatu bentuk penelitian yang intensif, terintegrasi dan mendalam.

\section{Teknik Pengumpulan Data}

Jenis data yang digunakan adalah data primer dan data sekunder. Data primer diperoleh dari perusahaan berupa hasil pengamatan langsung dan wawancara dengan pemilik PT. Dinaya Sambiana Loemintoe dengan bantuan kuesioner yang telah dipersiapkan sebelumnya. Data sekunder diperoleh dari dinas, intansi, lembaga yang berkaitan dengan penelitian ini.

\section{Teknik Penarikan Sampel}

PT. Dinaya Sambiana Loemintoe yang berada di Dusun Cikoranji Desa Cimindi Kecamatan Cigugur dipilih secara sengaja (purposive sampling) atas pertimbangan bahwa hanya ada satu perusahaan di Kecamatan Cigugur yang memproduksi keripik kelapa. Menurut Endraswara (2006) purposive sampling artinya bertujuan atau sengaja, penyampelan dilakukan dengan menyesuaikan gagasan, asumsi, sasaran, tujuan, dan manfaat yang hendak digapai oleh peneliti.

Sedangkan untuk penarikan sampel lembaga pemasaran dilakukan dengan cara Snow Ball Sampling. Endra (2017), menyatakan bahwa Snow Ball Sampling Method adalah teknik penentuan sampel yang mula-mula jumlahnya kecil atau sedikit, kemudian membesar, gambarannya seperti menggelindingkan bola salju. 


\section{Rancangan Analisis Data}

1. Untuk mengetahui saluran pemasaran keripik kelapa, digunakan analisis deskriptif kualitatif.

2. Untuk mengetahui biaya pemasaran keripik kelapa, digunakan rumus sebagai berikut (Angipora 2002) :

$\mathrm{TC}=\mathrm{Mm}-\pi$

Dimana :

TC = Total biaya pemasaran di tingkat lembaga pemasaran

$$
\begin{array}{ll}
\mathrm{Mm} & =\text { Marjin pemasaran } \\
\pi & =\text { Keuntungan di tingkat } \\
& \text { lembaga pemasaran }
\end{array}
$$

3. Untuk mengetahui marjin pemasaran keripik kelapa, digunakan rumus sebagai berikut (Angipora 2002) :

$\mathrm{Mm}=\mathrm{Pe}-\mathrm{Pf}$

Dimana :

$\mathrm{Mm} \quad=$ Marjin pemasaran

$\mathrm{Pe}=$ Harga produk di tingkat eceran $(\mathrm{Rp} / \mathrm{Kg})$

Pf $=$ Harga produk di tingkat produsen $(\mathrm{Rp} / \mathrm{Kg})$

1 Untuk mengetahui keuntungan pemasaran keripik kelapa, digunakan rumus sebagai berikut (Angipora 2002):

$\pi=\mathrm{Mm}-\mathrm{TC}$

Dimana :

$\pi=$ Kentungan di tingkat lembaga pemasaran

$$
\begin{array}{ll}
\mathrm{Mm} & =\text { Marjin pemasaran } \\
\mathrm{TC} & =\text { Total biaya pemasaran } \mathrm{di}
\end{array}
$$
tingkat lembaga pemasaran

4. Efisiensi pemasaran dihitung dengan menggunakan rumus (Angipora, 2002)

$$
\mathrm{EPS}=\frac{\mathrm{TBP}}{\mathrm{TNP}} \times 100 \%
$$

Keterangan :

EPS $=$ Efisiensi Pemasaran

$\mathrm{TBP}=$ Total Biaya Pemasaran $(\mathrm{Rp})$

TNP = Total Nilai Produk (Rp)

Kriteria hasil perhitungan :
a. $0-33 \%=$ Efisien
b. $34-67 \%=$ Kurang Efisien
c. $68-100 \%=$ Tidak Efisien

\section{Tempat dan Waktu Penelitian}

Lokasi penelitian ini dilaksanakan di Dusun Cikoranji Desa Cimindi Kecamatan Cigugur Kabupaten Pangandaran. Adapun waktu penelitian ini dilaksanakan dalam beberapa tahap sebagai berikut :

1. Tahapan survey pendahuluan, penulisan Usulan Penelitian dan Seminar Usulan Penelitian dilaksanakan pada bulan Februari s/d April 2019.

2. Tahapan pengumpulan dan pengolahan data dilaksanakan pada bulan April s/d Mei 2019. 
3. Tahapan penulisan laporan hasil penelitian (Skripsi) dilaksanakan pada bulan Juni 2019 sampai dengan selesai.

\section{HASIL DAN PEMBAHASAN}

\section{Identitas Responden}

\section{Umur Respon}

$\begin{array}{ccc}\text { Umur adalah faktor yang } \\ \text { mempengaruhi } & \text { terhadap keberhasilan }\end{array}$ dalam melakukan sutau kegiatan usaha dan juga akan berpengaruh terhadap kemampuan fisik dalam bekerja dan cara berfikir. Berdasarkan hasil penelitian diketahui bahwa umur responden berkisar antara 25 tahun sampai 60 tahun. Untuk lebih jelasnya dapat dilihat pada Tabel 8 .

\begin{tabular}{|c|c|c|c|c|c|c|}
\hline \multirow[t]{2}{*}{ No } & \multirow{2}{*}{ Responden } & \multicolumn{3}{|c|}{ Umur Responden } & \multicolumn{2}{|c|}{ Jumlah } \\
\hline & & 25-37 & 38-45 & 46-60 & Orang & $\%$ \\
\hline 1 & Produsen & & & 1 & 1 & 0,76 \\
\hline 2 & Agen & & 1 & 1 & 2 & 15,38 \\
\hline 3 & Pedagang pengecer & 1 & 4 & 5 & 10 & 76,92 \\
\hline & Total & 1 & 5 & 7 & 13 & 100 \\
\hline
\end{tabular}

Sumber : Analisis Data Primer, 2019

Tabel 8. Menunjukkan bahwa umur responden berada pada usia produktif yaitu 15-64 tahun.

\section{Keadaan Pendidikan}

Tingkat pendidikan merupakan faktor yang sangat menentukan terhadap seseorang dalam melaksanakan kegiatan usaha, karena dalam pola pikir orang yang berpendidikan rendah sangat berbeda jauh dengan orang yang berpendidikan lebih tinggi, sehingga dalam penerimaan hal-hal yang baru lebih sulit bagi yang berpendidikan rendah, dalam suatu usaha juga ditentukan pula apakah orang tersebut bisa mengelola dengan baik atau tidak. Keadaan responden berdasarkan tingkat pendidikan dapat dilihat pada Tabel 9. 
Tabel 9. Tingkat Pendidikan Responden

\begin{tabular}{|c|c|c|c|c|c|c|}
\hline \multirow{2}{*}{ No } & \multirow{2}{*}{ Responden } & \multirow{2}{*}{ Produsen } & \multirow{2}{*}{ Agen } & \multirow{2}{*}{$\begin{array}{l}\text { Pedagang } \\
\text { pengecer }\end{array}$} & \multicolumn{2}{|c|}{ Jumlah } \\
\hline & & & & & Orang & $\%$ \\
\hline 1 & SMP Sederajat & & & 7 & 7 & 53,84 \\
\hline 2 & SMA Sederajat & & 2 & 3 & 3 & 23,07 \\
\hline 3 & Perguruan Tinggi & 1 & & & 1 & 07,69 \\
\hline & Total & 1 & 2 & 10 & 13 & 100 \\
\hline
\end{tabular}

Sumber : Analisis Data Primer, 2019

Tabel 9. Menunjukkan bahwa sebagian besar tingkat pendidikan responden yaitu lulusan Sekolah Menengah Pertama yaitu sebanyak 7 orang, dengan demikian maka dapat disimpulkan secara keseluruhan responden belum memiliki rasa tenrang pentingnya wajib belajar.

\section{Tanggungan Keluarga}

Banyaknya jumlah tanggungan keluarga akan berpengaruh terhadap tingkat kesejahteraan keluarga. Keadaan responden berdasarkan tanggungan keluarga dapat dilihat pada Tabel 10.

Tabel 10. Tanggungan Keluarga Responden

\begin{tabular}{ccccccc}
\hline No. & $\begin{array}{c}\text { Tanggungan } \\
\text { Keluarga }\end{array}$ & Produsen & Agen & $\begin{array}{c}\text { Pedagang } \\
\text { Pengecer }\end{array}$ & \multicolumn{2}{c}{ Jumlah } \\
Orang & $\%$ \\
\hline 1. & $1-3$ & & 2 & 9 & 11 & 1. \\
2. & $>3$ & 1 & & 1 & 2 & 2. \\
\hline \multicolumn{2}{c}{ Total } & $\mathbf{1}$ & $\mathbf{2}$ & $\mathbf{1 0}$ & $\mathbf{1 3}$ & $\mathbf{1 0 0}$
\end{tabular}

Sumber : Analisis Data Primer, 2019

Tabel 10. Menunjukkan, bahwa berdasarkan hasil penelitian diketahui bahwa sebagian besar responden yang memiliki tanggungan keluarga antara 1 sampai 3 orang yaitu sebanyak 4 orang, dan responden yang memiliki tanggungan keluarga lebih dari 3 orang yaitu sebanyak 9 orang mereka yang masih menjadi tanggungan keluarga adalah istri dan anak yang masih sekolah, belum menikah atau belum bekerja.
Pengalaman berusaha merupakan salah satu faktor yang dapat mempengaruhi usahanya. hal tersebut merupakan modal utama untuk lebih terampil dalam mengatasi kesulitankesulitan maupun hambatan-hambatan yang mungkin terjadi saat usaha tersebut berlangsung. Keadaan responden berdasarkan pengalaman usaha dapat dilihat pada Tabel 11. 
Tabel 11. Pengalaman Usaha Responden

\begin{tabular}{ccccccc}
\hline No. & $\begin{array}{c}\text { Pengalaman } \\
\text { Usaha }\end{array}$ & Produsen & Agen & $\begin{array}{c}\text { Pedagang } \\
\text { Pengecer }\end{array}$ & \multicolumn{2}{c}{ Agen } \\
\hline 1. & $1-3$ & & 2 & 9 & 11 & $\%$ \\
2. & $>3$ & 1 & & 1 & 2 & 2. \\
\hline & Total & $\mathbf{1}$ & $\mathbf{2}$ & $\mathbf{1 0}$ & $\mathbf{1 3}$ & $\mathbf{1 0 0}$ \\
\hline
\end{tabular}

Sumber : Analisis Data Primer, 2019

\section{Pengalaman Usaha}

Tabel 11. Menunjukkan, bahwa berdasarkan hasil penelitian, pengalaman berusaha responden antara 1 sampai 3 tahun sebanyak 11 orang, lebih dari 3 tahun sebanyak 2 orang.

\section{Saluran Pemasaran Keripik Kelapa}

Pemasaran merupakan salah satu

kegiatan utama yang dilakukan oleh petani maupun lembaga pemasaran guna mendapatkaan keuntungan yang sebesarbesarnya dalam memasarkan suatu komoditas maupun produk tertentu. Berdasarkan hasil penelitian pemasaran keripik kelapa pada PT. Dinaya Sambiana Loemintoe yang berada di Dusun Cikoranji Desa Cimindi Kecamatan Cigugur Kabupaten Pangandaran memiliki dua saluran pemasaran. Hal tersebut dapat diihat pada Gambar 2 :

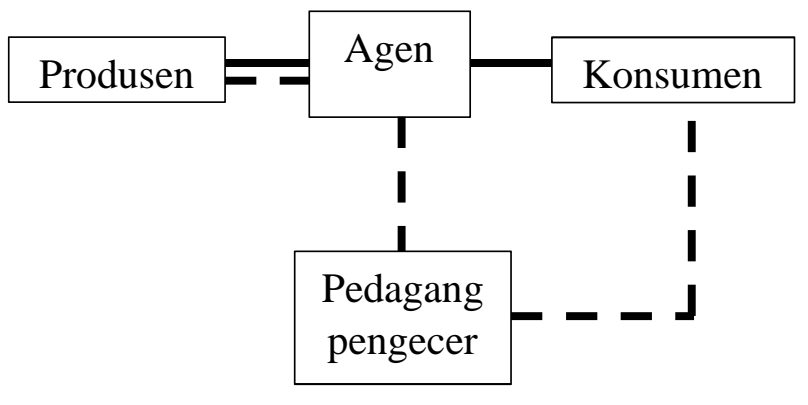

Gambar 2. Pola Saluran Pemasaran Keripik Kelapa

Keterangan :

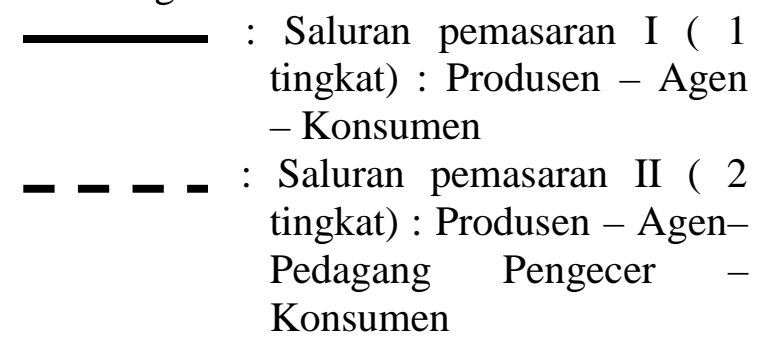

\section{Saluran Satu}

Saluran satu merupakan saluran satu tingkat, karena dalam proses penyampaian keripik kelapa dari produsen sampai ke konsumen melalui satu lembaga pemasaran, yaitu agen yang berada di Bandung sehingga dapat dikatakan saluran satu tingkat. Keripik kelapa dijual oleh produsen kepada agen dengan harga Rp. $28.000,00 / \mathrm{kg}$, penyaluran produk diantarkan dari Pangandaran ke Bandung 
dengan biaya yang ditanggung oleh pihak agen. Volume keripik kelapa yang dijual sebanyak $50 \mathrm{~kg}$, dan sampai ke konsumen dengan harga Rp. 45000,00/kg

\section{Saluran Dua}

Saluran dua merupakan saluran dua tingkat, karena dalam proses penyampaian keripik kelapa dari produsen sampai ke konsumen melalui dua lembaga pemasaran, yaitu agen dan pedagang pengecer yang berada di Bandung sehingga dapat dikatakan saluran dua tingkat. Keripik kelapa dijual oleh produsen kepada agen dengan harga Rp. $28.000,00 / \mathrm{kg}$, dengan volume penjualan sebanyak $1.330 \mathrm{~kg}$, penyaluran produk diantarkan dari Pangandaran ke Bandung dengan biaya yang ditanggung oleh pihak agen. Dari agen dijual ke pedagang pengecer dengan harga Rp. 40.000,00/kg yang diambil oleh pedagang pengecer sehingga agen tidak mengeluarkan biaya, dan pedagang pengecer menjual ke konsumen Rp. 53.500,00/kg.

\section{Analisis Biaya Pemasaran}

Biaya Pemasaran adalah penjumlahan dari biaya yang dikeluarkan untuk setiap satu kali proses pemasaran per $\mathrm{kg}$ di setiap lembaga pemasaran, yang terdiri dari biaya bongkar muat, biaya transportasi dan biaya retribusi. Untuk lebih jelasnya dapat dilihat pada Tabel 12 :
Tabel 12. Besarnya Biaya Pemasaran di Tiap Saluran Pemasaran Kerpik Kelapa pada PT. Dinaya Sambiana Loemintoe yang Berada di Dusun Cikoranji Desa Cimindi Kecamatan Cigugur Kabupaten Pangandaran

\begin{tabular}{|c|c|c|c|}
\hline No & Uraian & $\begin{array}{c}\text { Saluran I } \\
(\mathrm{Rp} / \mathrm{kg})\end{array}$ & $\begin{array}{c}\text { Saluran } \\
\text { II }(\mathbf{R p} / \mathbf{k g}) \\
\end{array}$ \\
\hline \multirow[t]{2}{*}{1.} & $\begin{array}{l}\text { Agen } \\
\text { - Bongkar muat } \\
\text { - Transportasi } \\
\text { - Retribusi }\end{array}$ & $\begin{array}{r}150,00 \\
2.000,00 \\
100,00\end{array}$ & $\begin{array}{l}150,00 \\
300,75 \\
100,00\end{array}$ \\
\hline & Jumlah & $2.250,00$ & $\mathbf{5 5 0 , 7 5}$ \\
\hline \multirow[t]{3}{*}{2.} & $\begin{array}{l}\text { Pedagang } \\
\text { pengecer } \\
\text { - Kemasan } \\
\text { - Biaya Angkut }\end{array}$ & $\begin{array}{l}- \\
-\end{array}$ & $\begin{array}{r}300,00 \\
723,648\end{array}$ \\
\hline & Jumlah & $2.250,00$ & $1.023,648$ \\
\hline & Total Biaya & $2.250,00$ & $1.574,398$ \\
\hline
\end{tabular}

Sumber : Analisis Data Primer, 2019

Berdasarkan Tabel 12 diatas menunjukkan bahwa besarnya biaya pemasaran di tiap saluran pemasaran pada saluran I untuk agen meliputi biaya bongkar muat, transportasi dan retribusi yaitu Rp 2.250,00/kg, sedangkan pada saluran II untuk agen meliputi biaya bongkar muat, transportasi dan retribusi yaitu Rp 550,75/kg. sedangkan untuk pedagang pengecer yaitu meliputi kemasan dan biaya angkut Rp 1.023,648/kg

\section{Analisis Marjin dan Keuntungan Pemasaran}

Marjin pemasaran adalah perbedaan harga yang diterima produsen 
dengan harga yang dibayar konsumen. Untuk lebih jelasnya dapat dilihat pada Tabel 13 :

Tabel 13. Besarnya Marjin dan Keuntungan Pemasaran di Tiap Saluran Pemasaran Keripik Kelapa pada PT. Dinaya Sambiana Loemintoe yang berada di Dusun Cikoranji Desa Cimindi Kecamatan Cigugur Kabupaten Pangandaran

\begin{tabular}{llrr}
\hline \hline No & Unsur Pemasaran & Saluran I (Rp) & Saluran II (Rp) \\
\hline \hline 1. & Produsen & $28.000,00$ & $28.000,00$ \\
\hline 2. & Agen & & \\
& Harga Beli & $28.000,00$ & $28.000,00$ \\
& Harga Jual & $45.000,00$ & $40.000,00$ \\
Marjin Pemasaran & & $\mathbf{1 2 . 0 0 0 , 0 0}$ \\
& Biaya Pemasaran & $\mathbf{1 7 . 0 0 0 , 0 0}$ & 550,75 \\
& Keuntungan & & $\mathbf{1 1 . 4 4 9 , 2 5}$ \\
& & $2.250,00$ & \\
& Pedagang Pengecer & $\mathbf{1 4 . 7 5 0 , 0 0}$ & $40.000,00$ \\
& Harga Beli & - & $53.500,00$ \\
& Harga Jual & - & $\mathbf{1 3 . 5 0 0 , 0 0}$ \\
& Marjin Pemasaran & - & $1.023,649$ \\
& Biaya Pemasaran & - & $\mathbf{1 1 . 2 6 3 , 4 2 0}$ \\
\hline Keuntungan & - & $\mathbf{2 5 . 5 0 0 , 0 0}$ \\
\hline & & $\mathbf{2 2 . 7 1 2 , 6 7}$ \\
\hline \hline
\end{tabular}

Sumber : Analisis Data Primer, 2019

Berdasarkan Tabel 13 diatas diketahui bahwa marjin pemasaran di tiap saluran pemasaran pada saluran I untuk agen sebesar $\mathrm{Rp} 17.000,00 / \mathrm{kg}$ marjin pemasaran pada saluran II untuk agen sebesar Rp 12.000,00/kg dan pedagang pengecer sebesar Rp 13.500,00/kg. Sedangkan keuntungan pemasaran di tiap saluran pemasaran pada saluran I untuk agen sebesar Rp 14.750,00/kg, keuntungan pada saluran II untuk agen sebesar Rp $11.449,25 / \mathrm{kg}$ dan pedagang pengecer sebesar Rp 11.263,420/kg.

4. Efisiensi Pemasaran

Efisiensi pemasaran merupakan perbandingan antara total biaya pemasaran dengan total nilai produk yang dipasarkan dikalikan seratus persen, dinyatakan dalam presentase (\%). Untuk lebih jelasnya dapat dilihat pada Tabel 14 : 
Tabel 14. Efisiensi Pemasaran di Tiap Saluran Pemasaran Keripik Kelapa pada PT. Dinaya Sambiana Loemintoe yang berada di Dusun Cikoranji Desa Cimindi Kecamatan Cigugur Kabupaten Pangandaran

\begin{tabular}{|c|c|c|c|c|c|}
\hline No & Saluran & TBP & TNP & $\begin{array}{l}\text { TBP } \\
\text { TNP }\end{array}$ & Efisiensi (\%) \\
\hline 1. & Saluran I & $2.250,00$ & $45.000,00$ & 0,05 & 0,5 \\
\hline 2. & Saluran II & 550,75 & $53.500,00$ & 0,010 & 1,0 \\
\hline
\end{tabular}

Sumber : Analisis Data Primer, 2019

Berdasarkan Tabel 14 diatas, dapat diketahui bahwa kedua saluran pemasaran keripik kelapa pada PT. Dinaya Sambiana Loemintoe yang berada di Dusun Cikoranji Desa Cimindi Kecamatan Cigugur Kabupaten Pangandaran dikatakan efisien. Untuk saluran I nilai efisiensi pemasarannya yaitu sebesar 0,5 persen, sedangkan saluran II sebesar 1,0 persen. Hasil penelitian menunjukkan bahwa Saluran I lebih efisien dibandingkan saluran II karena nilai efisiensinya lebih kecil. Hasil penelitian ini sejalan dengan teori yang dikemukakan oleh para ahli yang menyebutkan bahwa saluran pemasaran dikatakan efisien apabila nilai efisiensi pemasarannya tidak lebih dari 0$33 \%$.

\section{KESIMPULAN DAN SARAN}

\section{Kesimpulan}

Berdasarkn hasil penelitian dan pembahasan, maka dapat ditari kesimpulan sebagai berikut :
1. Saluran Pemasaran Keripik Kelapa pada PT. Dinaya Sambiana Loemintoe yang berada di Dusun Cikoranji Desa Cimindi Kecamatan Cigugur Kabupaten Pangandaran terbagi menjadi dua pola saluran pemasaran, yaitu :
a. Saluran I : Produsen - Agen - Konsumen
b. Saluran II : Produsen - Agen - Pedagang Pengecer - Konsumen

2. Biaya Pemasaran di Tiap Saluran Pemasaran pada saluran I untuk agen meliputi biaya bongkar muat, transportasi dan retribusi yaitu $R p$ $2.250,00 / \mathrm{kg}$, sedangkan pada saluran II untuk agen meliputi biaya bongkar muat, transportasi dan retribusi yaitu Rp 550,75/kg. sedangkan untuk pedagang pengecer yaitu meliputi biaya angkut $\mathrm{Rp} 1.023,648 / \mathrm{kg}$

3. Marjin pemasaran dan keuntungan di Tiap Saluran Pemasaran pada saluran I untuk agen sebesar Rp 17.000,00/kg 
marjin pemasaran pada saluran II untuk agen sebesar Rp 12.000,00/kg dan pedagang pengecer sebesar Rp 13.500,00/kg. Sedangkan keuntungan pemasaran di tiap saluran pemasaran pada saluran I untuk agen sebesar Rp 14.750,00/kg, keuntungan pada saluran II untuk agen sebesar $\mathrm{Rp}$ $11.449,25 / \mathrm{kg}$ dan pedagang pengecer sebesar Rp 11.263,420/kg.

4. Efisiensi Pemasaran menunjukan bahwa pada saluran I nilai efisiensi pemasarannya yaitu sebesar 0,5 persen, sedangkan saluran II sebesar 1,0 persen. Hasil penelitian menunjukkan bahwa Saluran I lebih efisien dibandingkan saluran II karena nilai efisiensinya lebih kecil. Hasil penelitian ini sejalan dengan teori yang dikemukakan oleh para ahli yang menyebutkan bahwa saluran pemasaran dikatakan efisien apabila nilai efisiensi pemasarannya tidak lebih dari 0-33\%.

\section{Saran}

Berdasarkan hasil penelitian yang telah dilakukan, maka sangat disarankan kepada para pelaku lembaga pemasaran untuk mengefektifkan dan memperpendek rantai tataniaga, sehingga dapat memperkecil biaya pemasaran, dan menjadikan proses pemasaran lebih efisien.

\section{DAFTAR PUSTAKA}

Abidin Z, Dkk. 2017. Pemasaran Hasil Perikanan. UB Press. Malang.

Angipora. 2002. Dasar-dasar Pemasaran, Edisi Kedua. Raja Grafindo Persada. Jakarta.

Deliarnov. 2006. Ekonomi Politik. Penerbit Erlangga. Jakarta..

Endra F. 2017. Pedoman Metodologi Penelitian. Zafatama Jawara. Sidoarjo.

Endraswara S. Metode, Teori, Teknik Penelitian Kebudayaan, Ideologi, Epstermologi Dan Aplikasi. Yogyakarta : Pustaka Widyatama. 2006.

Faqih, A. 2010. Manajemen Agribisnis. Dee Publish. Yogyakarta.

Sjamsir, Z. 2009. Pembangunan Pertanian Dalam Pusaran Kearipan Lokal. CV Sah Media. Makasar.

Suryanto, H,M. 2017. Metode Riset Dan Analisis Saluran Distribusi. PT Grasindo. Jakarta.

Waluya B. 2004. Menyelami Fenomena Sosial Di Masyarakat. PT Setia Putra Inves. Bandung

Winarno. 2014. Kelapa Pohon Kehidupan. PT Gramedia Pustaka Utama. 